\title{
ALTERAÇÕES NOS NÍVEIS RELATIVOS DE AÇÚCARES SOLÚVEIS TOTAIS E DE PROTEÍNAS EM PLANTAS DE MILHO INFECTADAS COM MOLICUTES ${ }^{1}$
}

\author{
PAULO CÉSAR MAGALHÃES ${ }^{2}$, ELIZABETH DE OLIVEIRA ${ }^{3}$, ISABEL R. P. SOUZA ${ }^{3}$, FREDERICO \\ O. M. DURÃES ${ }^{3}$, CHARLES M. OLIVEIRA $^{4}$ E ANTÔNIO CARLOS DE OLIVEIRA $^{3}$ \\ ${ }^{1}$ Apoio $\mathrm{CNPq} /$ Prosul \\ ${ }^{2}$ Bolsista do CNPq, Pesquisador Embrapa Milho e Sorgo, C. P. 151, CEP: 35701-970 - Sete Lagoas, MG, E-mail: \\ pcesar@cnpms.embrapa.br, ${ }^{3}$ Pesquisadores Embrapa Milho e Sorgo, ${ }^{4}$ Pesquisador, Embrapa Cerrados, Brasília, DF.
}

Revista Brasileira de Milho e Sorgo, v.4, n.3, p.335-343, 2005

\begin{abstract}
RESUMO - As doenças do milho causadas por molicutes (fitoplasma e espiroplasma) destacam-se em importância para a cultura, em consequiência da alta incidência e dos prejuízos que causam à produção de grãos. Os molicutes infectam o floema das plantas; sendo assim, podem alterar a síntese de açúcares e proteínas. O objetivo deste trabalho foi verificar o efeito dos molicutes na síntese de açúcares solúveis totais e de proteínas em duas cultivares de milho. O experimento foi conduzido em vasos de plástico contendo $30 \mathrm{~kg}$ solo previamente analisado e adubado, com duas plantas por vaso. O delineamento experimental utilizado foi um fatorial $3 \times 2$ inteiramente casualizado, com seis repetições; sendo três inoculações (fitoplasma, espiroplasma e sadia) e duas cultivares (Dina 766 e BR 201). Trinta dias após a inoculação, foram realizadas medidas de temperatura foliar, umidade relativa, resistência estomática e transpiração. No estádio de grão leitoso, uma das plantas foi colhida e seccionada em três partes, para análise de açúcares solúveis totais, nutrientes e matéria seca. Foi realizada uma amostragem do internódio abaixo da primeira espiga e da folha bandeira, para determinação da atividade da peroxidase e do conteúdo proteíco. A planta restante foi conduzida até o final do ciclo, quando foram avaliados: número de espigas, peso de espigas e de grãos e matéria seca dos grãos. A análise de variância de todas as características avaliadas não detectou significância na interação cultivar x inoculação. Alguns parâmetros mostraram significância para cultivares, para inoculação ou para ambos. Açúcares solúveis, matéria seca, atividade da peroxidase e conteúdo protéico foram semelhantes em ambas as cultivares e nas inoculações. A resistência estomática foi maior para Dina 766 e nas plantas inoculadas por fitoplasma. A proliferação de espigas foi maior nas plantas inoculadas pelos molicutes que nas sadias. O peso de espigas e de grãos foi maior nas plantas sadias e com fitoplasma que naquelas infectadas por espiroplasma. Concentração de nutrientes e quantidade absorvida, em geral, foram semelhantes, excetuando $\mathrm{P}$ e Zn. Os molicutes não interferiram na concentração dos açúcares solúveis e no conteúdo proteíco total; entretanto, os dados de produtividade sugerem uma maior susceptibilidade das cultivares ao espiroplasma.
\end{abstract}

Palavras-chave: Zea mays L., proteína, espiroplasma, fitoplasma, carboidratos.

\section{ALTERATIONS IN SOLUBLE SUGAR LEVELS, AND PROTEINS CONCENTRATION IN MAIZE CULTIVARS INOCULATED BY MOLLICUTES}

\begin{abstract}
Maize diseases caused by mollicutes (Phytoplasma and Spiroplasma) are important for the crop because its high incidence causes losses in grain production. Plants
\end{abstract}


phloem are infected by mollicutes, which may alter sugar synthesis and proteins levels. The objective of this study was to verify the mollicutes effect on total soluble sugar and proteins synthesis in two maize cultivars. The experiment was carried out in pots of 30 $\mathrm{Kg}$, with soil previously analyzed and fertilized. After thinning two plants were left per pot. The experimental design was a fully randomized $3 \times 2$ factorial with 6 replications; being 3 inoculations (phytoplasma, spiroplasma and healthy plants) and 2 cultivars (Dina 766 and BR 201). Thirty days after inoculating maize plants, it was analyzed the parameters: leaf temperature, relative humidity, stomatal resistance and transpiration. At milky growth stage the maize plants were harvested and cut into 3 parts, in order to analyze total soluble sugars, nutrients and dry matter accumulation. The internode below main ear and the flag leaf were sampled to determine the peroxidase activity and protein content, respectively. The other plant was left up to end of the crop cycle in order to evaluate ear number, grain and ear weight and grain dry matter. The analysis of variance for all characteristics evaluated did not show significance on interactions of genotypes $\mathrm{x}$ inoculation. Some parameters resulted in significance for genotypes, inoculation or for both. Soluble sugars, dry matter, peroxidase activity and protein were similar in both genotypes and inoculations. Stomatal resistance was higher in Dina 766 and in maize plants inoculated by phytoplasma. Ear number was higher in plants inoculated by mollicutes than in healthy plants. Ear and grain weights were higher in healthy plants and in the ones infected by phytoplasma, when compared to the ones infected by spiroplasma. Nutrient concentration and the amounts taken up were similar, except for $\mathrm{P}$ and $\mathrm{Zn}$. The mollicutes interfered neither on soluble sugar synthesis nor on protein content. However, the yield data suggested a higher susceptibility to the Spiroplasma rather than to the Phytoplasma.

Key words: Zea mays L., carbohydrates, protein, spiroplasma, phytoplasma,

As doenças do milho causadas por molicutes (fitoplasma e espiroplasma) denominadas, respectivamente, enfezamento vermelho e enfezamento pálido, destacam-se em importância para essa cultura, em consequiência dos prejuízos que causam à produção de grãos (Massola et al., 1999, Oliveira et al., 2004). Os molicutes infectam o floema das plantas, sendo transmitidos de forma persistente pela cigarrinha Dalbulus maidis (Nault, 1980). Em campo, as cigarrinhas migram de lavouras doentes, em fase de produção, e infectam plântulas sadias, em novas lavouras, porém os sintomas dos enfezamentos geralmente se manifestam somente quando as plantas entram em fase de produção. Contudo, sob condições controladas, plântulas de milho infectadas, seja com fitoplasma ou com espiroplasma, podem apresentar sintomas dessas doenças cerca de 30 dias após a inoculação, sendo o aparecimento favorecido por temperaturas acima de $30{ }^{\circ} \mathrm{C}$ (Nault, 1980; Oliveira et al., 2002a). Molicutes afetam a performance e o crescimento das plantas de milho, reduzem sua absorção de nutrientes, principalmente $\mathrm{Mg}$ e $\mathrm{P}$ e, aparentemente, interferem nos processos de translocação de fotoassimilados para o enchimento de grãos (Oliveira 2000;; Magalhães et al., 2002; Oliveira et al., 2002b). O efeito dos molicutes no encurtamento dos internódios, na redução da matéria seca das plantas e dos grãos e na proliferação de espigas já é bem conhecido (Magalhães et al., 2001). A possível interferência do fitoplasma e ou do 
espiroplasma na síntese dos açúcares e de proteínas não é conhecida em plantas de milho. Uma interferência nessa síntese poderia comprometer o enchimento de grãos, desde que a planta de milho nesse estádio demande uma quantidade grande de fotoassimilados para atender suas necessidades. (Magalhães et al. 1998; Magalhães et al., 1999). Arias et al. (2003), pesquisando as alterações no metabolismo de carbono em plantas de girassol infectadas por "Sunflower Chlorotic Mottle Virus", concluíram que, após os sintomas se tornarem evidentes as taxas de fixação de $\mathrm{CO}_{2}$ decresceram; no entanto, açúcares solúveis e amido aumentaram em folhas infectadas. $\mathrm{O}$ conhecimento sobre os mecanismos fisiológicos pelos quais os molicutes interferem sobre o crescimento e a produção das plantas de milho poderia contribuir para a elucidação de mecanismos de resistência do milho aos enfezamentos. Esses parâmetros poderão fornecer subsídios para a seleção de genótipos de milho tolerantes aos molicutes.

O objetivo deste trabalho foi verificar o efeito de molicutes na concentração de açúcares solúveis, de proteínas e de nutrientes, em plantas de milho.

\section{Material e Métodos}

Foram utilizadas duas cultivares de milho, Dina 766 e BR 201. O experimento foi conduzido em vasos de plástico contendo $30 \mathrm{~kg}$ de solo, previamente analisado e adubado conforme recomendação baseada na análise. Foram semeadas quatro sementes por vaso e, após o desbaste, foram deixadas duas plantas por vaso. $\mathrm{O}$ experimento foi disposto em delineamento inteiramente casualizado em esquema fatorial $3 \mathrm{x}$ 2 , contendo seis repetições e os seguintes tratamentos: três inoculações (fitoplasma, espiroplasma e sadia) e duas cultivares (Dina 766 e BR 201).
Para inoculação, cigarrinhas infectadas com fitoplasma, cigarrinhas infectadas com espiroplasma e cigarrinhas sadias foram confinadas em número de três por planta, de acordo com os tratamentos. A obtenção das cigarrinhas infectantes e a inoculação foram feitas conforme metodologia descrita por Oliveira et al. (2004). Trinta dias após as inoculações, foram realizadas medidas, na primeira folha completamente expandida do ápice para baixo (Magalhães, 2003), da temperatura foliar, da umidade relativa, da resistência estomática e da transpiração. $\mathrm{O}$ aparelho utilizado nessas mensurações foi o porômetro do estágio do equilíbrio, da Licor, modelo LI-1600. No estádio de grão leitoso, uma das plantas foi colhida e dividida em três partes (superior, mediana e basal), para análise de açúcares solúveis totais, matéria seca e macronutrientes. Foi também realizada uma amostragem do internódio abaixo da primeira espiga e da folha bandeira, para determinação da atividade da peroxidase e do conteúdo protéico total (Lopes, 2005). A planta restante foi conduzida até o final do ciclo, quando foram avaliados: número de espigas, peso de espigas, peso de grãos e matéria seca dos grãos. A matéria seca, tanto da parte aérea como dos grãos, foi obtida em estufa de ventilação forçada, na temperatura de $70^{\circ} \mathrm{C}$, após os valores atingirem o peso constante.

\section{Resultados e Discussão}

A análise de variância de todas as características avaliadas não detectou significância para o efeito das inoculações, tampouco para a interação cultivar x inoculação. Algumas características, no entanto, mostraram significância para interação cultivares x partes da planta e para alguns efeitos isolados dos outros tratamentos.

Açúcares solúveis totais e matéria seca foram semelhantes em ambas as cultivares, as- 
sim como para o fator inoculação (Figuras 1 e 2). Este resultado mostra que, no estádio de grão leitoso, as doenças causadas por molicutes não interferiram na movimentação e no processo de síntese de açúcares na planta, tampouco na acumulação de matéria seca. Embora o fator quantitativo não tenha sido avaliado nesta pesquisa, é possível que a quantidade de inóculo presente na planta não tenha sido suficiente para interferir nesses processos. O fato de os molicutes não interferirem no acúmulo de matéria seca diverge dos resultados encontrados por Oliveira et al. (2002b), que relataram maior acumulação de matéria seca nas plantas sadias, comparadas com as doentes.

Quando se analisaram separadamente as três partes da planta, a matéria seca da parte mediana foi maior que das partes superior e inferior

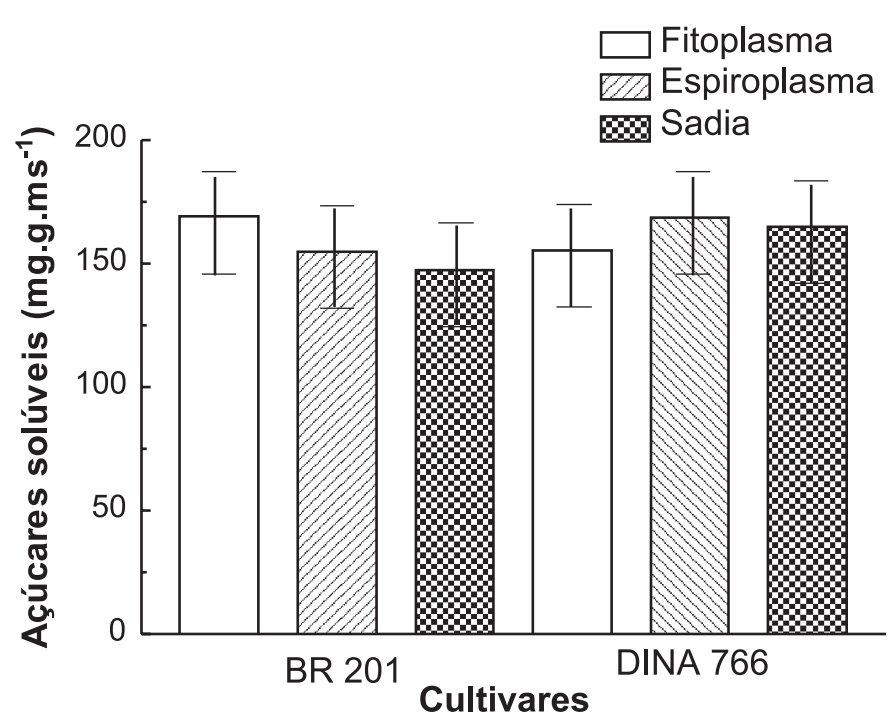

FIGURA 1. Teor de açúcares solúveis totais em plantas submetidas à inoculação com molicutes.

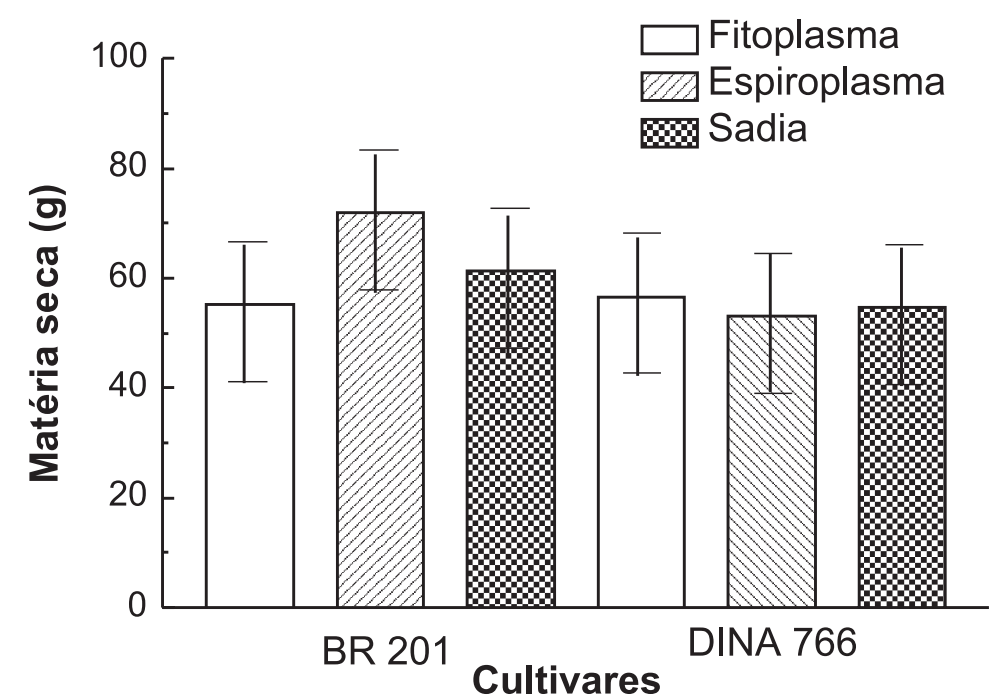

FIGURA 2. Matéria seca de plantas submetidas à inoculação com molicutes. 
e a porcentagem de açúcares solúveis foi maior na parte superior da planta (Tabela 1). Esse resultado relacionado ao maior teor de açúcares solúveis na parte superior da planta é plenamente justificado pela atividade metabóli- ca das folhas superiores, as quais estão menos sombreadas, com maiores taxas fotossintéticas e, portanto, com maior teor de açúcares (Magalhães \& Jones 1990, Magalhães et al., 2003).

TABELA 1. Peso da matéria seca e teor de açúcares solúveis totais em três diferentes partes de plantas de milho.

\section{Características}

\begin{tabular}{ccc}
\cline { 2 - 3 } Parte da planta & Matéria seca $(\mathbf{g})$ & Açúcares solúveis $\left(\mathbf{m g ~ g ~ m s ~}^{\mathbf{- 1}}\right)$ \\
\hline Superior & $37,05^{1} \mathrm{~B}$ & $200,04 \mathrm{~A}$ \\
Mediana & $96,76 \mathrm{~A}$ & $170,07 \mathrm{~B}$ \\
Inferior & $42,78 \mathrm{~B}$ & $100,86 \mathrm{C}$ \\
\hline
\end{tabular}

${ }^{1}$ Médias seguidas da mesma letra, na vertical não diferem entre si ao nível de 5\% de probabilidade, pelo teste de Duncan.

Com relação à concentração de nutrientes (Tabela 2), somente P e Zn apresentaram diferenças estatiscamente significativas entre os tratamentos. O teor de fósforo foi maior nas plantas infectadas pelos molicutes do que nas sadias, resultado este semelhante àquele encontrado por Oliveira et al. (2002b), enquanto que o teor de zinco foi maior somente nas plantas infectadas por espiroplasma. Esses resultados demonstraram que os molicutes não interferiram na absorção da maioria dos nutrientes avaliados.

No que diz respeito à quantidade de nutrientes absorvida, apenas zinco foi diferente, tenha sido detectada maior absorção e acúmulo

TABELA 2. Médias para concentração de nutrientes $\left(\mathrm{mg} \mathrm{g} \mathrm{ms}^{-1}\right)$ em plantas sadias e plantas inoculadas por molicutes.

\begin{tabular}{|c|c|c|c|c|c|c|c|}
\hline \multirow[t]{2}{*}{ Molicute } & \multicolumn{7}{|c|}{$\begin{array}{l}\text { Nutrientes } \\
\left(\mathrm{mg} \mathrm{g} \mathrm{ms}^{-1}\right)\end{array}$} \\
\hline & $\mathbf{N}$ & $\mathbf{P}$ & $\mathbf{K}$ & $\mathrm{Ca}$ & Mg & $\mathrm{Zn}$ & Mn \\
\hline Fitoplasma & $14,7^{1} \mathrm{~A}$ & $1,3 \mathrm{~A}$ & $12,1 \mathrm{~A}$ & $4,4 \mathrm{~A}$ & $1,8 \mathrm{~A}$ & $104,0 \mathrm{~B}$ & $1304,7 \mathrm{~A}$ \\
\hline Espiroplasma & $14,1 \mathrm{~A}$ & $1,3 \mathrm{~A}$ & $12,1 \mathrm{~A}$ & $4,8 \mathrm{~A}$ & $1,7 \mathrm{~A}$ & $136,6 \mathrm{~B}$ & $1448,6 \mathrm{~A}$ \\
\hline Sadia & $13,2 \mathrm{~A}$ & $1,0 \mathrm{~B}$ & $12,0 \mathrm{~A}$ & $4,9 \mathrm{~A}$ & $1,9 \mathrm{~A}$ & $106,4 \mathrm{~B}$ & $1422,8 \mathrm{~A}$ \\
\hline CV (\%) & 12,26 & 14,60 & 24,55 & 29,89 & 19,33 & 20,53 & 34,77 \\
\hline
\end{tabular}

${ }^{1}$ Médias seguidas da mesma letra, na vertical, não diferem entre si ,ao nível de 5\% de probabilidade ,pelo teste de Duncan. 
desse nutriente nas plantas infectadas por espiroplasma (Tabela 3).
A atividade da peroxidase e o conteúdo protéico total foram semelhantes nos diversos

TABELA 3. Valores absolutos de nutrientes absorvida por plantas sadias e plantas inoculadas por molicutes.

Molicute

\begin{tabular}{cccccccc} 
& $\mathbf{N}(\mathbf{g})$ & $\mathbf{P}(\mathbf{g})$ & $\mathbf{K}(\mathbf{g})$ & $\mathbf{C a}(\mathbf{g})$ & $\mathbf{M g}(\mathbf{g})$ & $\mathbf{Z n}(\mathbf{m g})$ & $\mathbf{M n}(\mathbf{m g})$ \\
\hline Fitoplasma & $0,79^{1} \mathrm{~A}$ & $0,081 \mathrm{~A}$ & $0,61 \mathrm{~A}$ & $0,21 \mathrm{~A}$ & $0,087 \mathrm{~A}$ & $0,59 \mathrm{~B}$ & $6,22 \mathrm{~A}$ \\
Espiroplasma & $0,85 \mathrm{~A}$ & $0,088 \mathrm{~A}$ & $0,69 \mathrm{~A}$ & $0,25 \mathrm{~A}$ & $0,119 \mathrm{~A}$ & $0,88 \mathrm{~A}$ & $7,02 \mathrm{~A}$ \\
Sadia & $0,76 \mathrm{~A}$ & $0,062 \mathrm{~A}$ & $0,64 \mathrm{~A}$ & $0,23 \mathrm{~A}$ & $0,093 \mathrm{~A}$ & $0,63 \mathrm{AB}$ & $6,85 \mathrm{~A}$ \\
\hline CV (\%) & 52,05 & 69,46 & 49,57 & 43,64 & 69,37 & 56,73 & 52,20
\end{tabular}

${ }^{1}$ Médias seguidas da mesma letra, na vertical, não diferem entre si, ao nível de $5 \%$ de probabilidade, pelo teste de Duncan.

tratamentos (Tabela 4), mostrando que tanto espiroplasma como fitoplasma não interferem na síntese de proteínas. As principais proteínas armazenadas no grão de milho são as zeínas, conhecidas como prolaminas, devido à alta concentração de prolina e glutamina. As prolaminas não têm atividade enzimática, simplesmente fornecem fonte de aminoácidos, nitrogênio e esqueleto de carbono para as sementes em desenvolvimento (Shotwell \& Larkins, 1989).

A proliferação de espigas foi maior nas plantas inoculadas por molicutes do que nas sa- dias (Tabela 4). Esse efeito é devido a um desbalanço hormonal das plantas, provocando a quebra da dominância apical. A dominância apical é quebrada pela indução de fatores ambientais, bióticos ou abióticos, e pelo balanço hormonal endógeno. Experimentos indicam que a dormência da gema (a cessação do crescimento do meristema apical e da região subapical) pode ser regulada pelo balanço hormonal entre um inibidor de crescimento produzido nas folhas e as giberelinas endógenas. A passagem progressiva para a dormência envolve um aumento gra-

TABELA 4. Valores relativos de proteína, atividade da peroxidase e de produção em plantas de milho inoculadas por molicutes. Média de dois genótipos.

\begin{tabular}{|c|c|c|c|c|c|}
\hline \multirow[b]{2}{*}{ Molicute } & \multirow[b]{2}{*}{$\begin{array}{c}\text { Conteúdo rotéico } \\
\left(\mathrm{mg}^{-1} \mathrm{mf}\right)\end{array}$} & \multicolumn{4}{|c|}{ Característica } \\
\hline & & $\begin{array}{l}\text { Atividade da peroxidase } \\
\left(470 \mathrm{~min}^{-1} \mathrm{mg}^{-1} \text { proteína) }\right.\end{array}$ & $\begin{array}{l}\text { No. de } \\
\text { espigas }\end{array}$ & $\begin{array}{c}\text { Peso de } \\
\text { espigas (g) }\end{array}$ & $\begin{array}{c}\text { Peso de } \\
\text { grãos (g) }\end{array}$ \\
\hline Fitoplasma & $4,97^{1} \mathrm{~A}$ & $25543,46 \mathrm{~A}$ & $2,00 \mathrm{~A}$ & $268,21 \mathrm{~A}$ & $220,82 \mathrm{~A}$ \\
\hline Espiroplasma & $6,69 \mathrm{~A}$ & $22387,66 \mathrm{~A}$ & $2,67 \mathrm{~A}$ & $103,07 \mathrm{~B}$ & $79,15 \quad \mathrm{~B}$ \\
\hline Sadia & $5,04 \mathrm{~A}$ & $23834,37 \mathrm{~A}$ & $1,00 \mathrm{~B}$ & $251,58 \mathrm{~A}$ & $202,24 \mathrm{~A}$ \\
\hline
\end{tabular}

${ }^{1}$ Médias seguidas da mesma letra, na vertical não diferem entre si, ao nível de $5 \%$ de probabilidade, pelo teste de Duncan. 
dual no nível de inibidores presentes na planta, principalmente nas folhas e nas gemas terminais do caule. Esses inibidores pertencem ao grupo químico dos fenóis ou à categoria dos reguladores de crescimento naturais, como ABA - ácido abscíssico. A aplicação de ABA induz, em certas plantas, uma dormência semelhante àquela provocada por dias curtos. Esse efeito do ABA pode ser anulado pela aplicação de concentrações adequadas de giberelinas, reguladores promotores de crescimento (Dietrich, 1986).

O peso de espigas e de grãos foi maior nas plantas sadias e infectadas com fitoplasma do que naquelas infectadas por espiroplasma (Tabela 4). Esses resultados são discordantes, pelo menos parcialmente, daqueles mencionados por
Oliveira et al. (2002b), segundo os quais, plantas sadias resultaram em maior peso de grãos do que plantas infectadas por molicutes.

As características temperatura foliar e umidade relativa não resultaram em diferenças significativas para inoculação e genótipos (Tabelas 5 e 6). A resistência estomática foi maior nas plantas inoculadas com fitoplasma do que nas sadias e inoculadas com espiroplasma. Conseqüentemente, apresentaram menor transpiração foliar (Tabela 5). Esses resultados discordam parcialmente daqueles relatados por Magalhães et al. (2001), que encontraram maior resistência estomática em plantas inoculadas por molicutes do que em plantas sadias, sendo que, para transpiração, não foram encontradas diferenças

TABELA 5. Temperatura, umidade relativa, resistência estomática e transpiração em plantas de milho inoculadas por molicutes. Média de dois genótipos de milho.

\begin{tabular}{|c|c|c|c|c|}
\hline \multirow[b]{2}{*}{ Molicute } & \multicolumn{3}{|c|}{ Característica } & \multirow[b]{2}{*}{$\begin{array}{c}\text { Transpiração } \\
\left(\mathrm{mg} \mathrm{m}^{-2} \mathrm{~s}^{-1}\right)\end{array}$} \\
\hline & $\begin{array}{c}\text { Temper atura } \\
\text { foliar }\left({ }^{\circ} \mathrm{C}\right)\end{array}$ & $\begin{array}{c}\text { Umidade } \\
\text { relativa (\%) }\end{array}$ & $\begin{array}{c}\text { R. estomática } \\
\left(\mathrm{s} \mathrm{mm}^{-1}\right)\end{array}$ & \\
\hline Fitoplasma & $27,00^{1} \mathrm{~A}$ & $47,50 \mathrm{~A}$ & $45,1 \mathrm{~A}$ & $32,6 \mathrm{~B}$ \\
\hline Espiroplasma & $26,93 \mathrm{~A}$ & $47,80 \mathrm{~A}$ & $30,5 \mathrm{~B}$ & $45,6 \mathrm{~A}$ \\
\hline Sadia & $27,05 \mathrm{~A}$ & $47,07 \mathrm{~A}$ & $30,7 \mathrm{~B}$ & $45,3 \mathrm{~A}$ \\
\hline
\end{tabular}

${ }^{1}$ Médias seguidas da mesma letra, na vertical não diferem entre si, ao nível de $5 \%$ de probabilidade, pelo teste de Duncan.

TABELA 6. Temperatura, umidade relativa, resistência estomática e transpiração de dois genótipos de milho inoculadas por molicutes.

\begin{tabular}{|c|c|c|c|c|}
\hline \multirow[b]{2}{*}{ Genótipo } & \multicolumn{3}{|c|}{ Característica } & \multirow[b]{2}{*}{$\begin{array}{r}\text { Transpiração } \\
\left(\mathrm{mg} \mathrm{m}^{-2} \mathrm{~s}^{-1}\right)\end{array}$} \\
\hline & $\begin{array}{c}\text { Temperatura } \\
\text { foliar }\left({ }^{\circ} \mathrm{C}\right)\end{array}$ & $\begin{array}{c}\text { Umidade } \\
\text { relativa (\%) }\end{array}$ & $\begin{array}{c}\text { R. estomática } \\
\left(\mathrm{s} \mathrm{mm}^{-1}\right)\end{array}$ & \\
\hline BR 201 & $26,87^{1} \mathrm{~A}$ & $47,96 \mathrm{~A}$ & $30,4 \mathrm{~B}$ & $45,8 \mathrm{~A}$ \\
\hline Dina 766 & $27,12 \mathrm{~A}$ & $46,96 \mathrm{~A}$ & $40,5 \mathrm{~A}$ & $36,5 \mathrm{~B}$ \\
\hline
\end{tabular}

${ }^{1}$ Médias seguidas da mesma letra, na vertical não diferem entre si, ao nível de $5 \%$ de probabilidade, pelo teste de Duncan. 
significativas. A explicação para essa divergência é uma provável interação entre plantas infectadas por molicutes com umidade no solo, uma vez que, no trabalho de Magalhães et al. (2001), as plantas foram submetidas a quatro níveis de água no solo.

A cultivar Dina 766 apresentou maior resistência estomática e menor taxa transpiratória quando comparada ao BR 201(Tabela 6). O BR 201 é um híbrido com alto potencial de produção e com um desenvolvimento superior ao Dina 766, o que justifica, em parte, essas diferenças relacionadas à absorção de $\mathrm{CO}_{2}$ e taxas transpiratórias.

Os molicutes não interferiram na síntese dos açúcares solúveis e de proteínas. Entretanto, os dados de produtividade sugerem uma maior susceptibilidade das cultivares ao espiroplasma.

\section{Literatura Citada}

ARIAS, M. C.; LENARDON, S.; TALEINSNIK. Carbon metabolism alterations in sunflower plants infected with the Sunflower Chlorotic Mottle Virus. Phytopathology, St. Paul, v. 151, p. 267-273, 2003.

DIETRICH, S. .M. C. Mecanismos de ação dos reguladores de crescimento. In: FERRI, M .G. (Coord.). Fisiologia vegetal. 2. ed. São Paulo: EPU, 1986. p. 213-229.

LOPES, M. J. C. Estresse oxidativo e análise anatômica em plantas de diferentes ciclos de seleção do milho "Saracura BRS-4154" sob encharcamento contínuo. 2005. 65 f. Tese (Mestrado) - Universidade Federal de Lavras, Lavras.

MAGAlHÃES, P. C.; JONES, R. Aumento de fotoassimilados na taxa de crescimento e peso final dos grãos de milho. Pesquisa Agropecuária
Brasileira, Brasília, DF, v. 25, n. 12 p. 1747-1754, 1990.

MAGALHÃES, P. C.; DURÃES, F. O .M.; PORTILHO, N. C.; PAIVA, E. Fisiologia do milho. Sete Lagoas: EMBRAPA-CNPMS, 2003. 23 p. (EMBRAPA-CNPMS. Circular Técnica, 22).

MAGALHÃES, P. C.; DURÃES, F. O. M, OLIVEIRA, A. C. Efeitos do quebramento do colmo no rendimento de grãos de milho. Ciência e Agrotecnologia, Lavras, v.2, n. 3, p. 279-289, jul./set. 1998.

MAGALHÃES, P. C.; DURÃES, F. O. M; OLIVEIRA, A. C; GAMA, E. E. G. Efeitos de diferentes técnicas de despendoamento na produção de milho. Scientia Agricola, Piracicaba, v. 56, n. 1, p. 77-82, jan./mar. 1999.

MAGALHÃES, P. C.; OLIVEIRA, E.; GOMIDE, R. L.; VASCONCELOS, C. A.; SOUZA, I. R. P. Aspectos fisiológicos de plantas de milho infectadas por molicutes sob diferentes níveis de água no solo. Revista Brasileira de Fisiolologia Vegetal, Londrina, v. 13, n. 3, p. 293-301, 2001.

MASSOLA, JUNIOR, N. S.; BEDENDO, I. P.; AMORIM, L.; LOPES, J. R. S. Quantificação de danos causados pelo enfezamento vermelho e enfezamento pálido do milho em condições de campo. Fitopatologia Brasileira, Brasília, DF, v. 24, n. 2, p. 136-142, 1999.

NAULT, L. R. Maize bushy stunt and corn stunt: a comparison of disease symptoms, pathogen host ranges, and vectors. Phytopathology, St. Paul, v. 70, n. 7, p. 659-662, 1980.

OLIVEIRA, C. M. Variação genética entre populações de Dalbulus maidis (Delong \& Wolcott, 1923) (Hemiptera: Cicadellidae) e mecanismos de sobrevivência na entressafra 
do milho. 2000. 167 f. Tese (Doutorado) - Escola Superior de Agricultura "Luiz de Queiroz", Universidade de São Paulo, Piracicaba.

OLIVEIRA, E.; OLIVEIRA, C. M.; SOUZA, I. R. P.; MAGAlHÃES, P. C.; CRUZ, I. Enfezamentos em milho: expressão de sintomas foliares, detecção dos molicutes e interações com genótipos. Revista Brasileira de Milho e Sorgo, Sete Lagoas, v. 1, n. 1, p. 53-62, 2002a.

OLIVEIRA, E.; MAGALHÃES, P. C.; GOMIDE, R. L.; VASCONCELOS, C. A .; SOUZA, I. R. P.; SHAFFERT, R. Growth and nutrition of molicute infected maize. Plant Disease, St. Paul, v. 86, n. 9 , p. $945-949,2002$ b.
OLIVEIRA, E.; DUARTE, A. P.; CARVALHO, R. V.; OLIVEIRA, A .C. Molicutes e virus na cultura do milho no Brasil: caracterização e fatores que afetam sua incidência. In: OLIVEIRA, E. de; OLIVEIRA, C. M. de. (Ed.). Doenças em milho: molicutes, vírus, vetores, mancha por Phaeosphaeria. Sete Lagoas: Embrapa Milho e Sorgo; Brasília, DF: Embrapa Informação Tecnológica, 2004. p. 17-34.

SHOTWELL, M. A.; LARKINS, B. A . The biochemistry and molecular biology of seed storage proteins. In: MARCUS, A. (Ed.). The biochemistry of plants: a comprehensivetreatise, New York: Academic Press, 1989. p. 297-345. 